\title{
CXCL1 Regulation in Human Pulmonary Epithelial Cells by Tumor Necrosis Factor
}

\author{
Jiunn-Min Shieh ${ }^{a, f}$ Yih-Jeng Tsaib,c,d,e Chih-Jen Tsou ${ }^{b}$ Wen-Bin Wu ${ }^{b}$ \\ ${ }^{\mathrm{a} D e p a r t m e n t}$ of Internal Medicine, Chi-Mei Medical Center, Tainan, ${ }^{\mathrm{b}}$ School of Medicine, Fu-Jen Catholic \\ University, New Taipei City, 'Department of Otolaryngology, Shin Kong Wu Ho-Su Memorial Hospital,

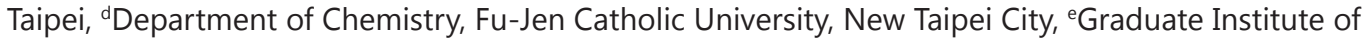 \\ Basic Medicine, Fu-Jen Catholic University, New Taipei City, Taiwan, 'The Center of General Education, \\ Chia Nan University of Pharmacy and Science, Tainan, Taiwan, ROC
}

\section{Key Words}

Chemokine $\cdot \mathrm{CXCL1} \cdot \mathrm{JNK} \cdot \mathrm{Gro}$ alpha $\cdot \mathrm{TNF} \cdot$ Signaling $\bullet$ Release $\cdot$ Secretion

\begin{abstract}
Background/Aims: The chemokine CXCL1 has been reported to be expressed in lung airway epithelium and non-small cell lung cancer biopsy specimens. In this study, we investigated the effects of TNF- $\alpha$, an abundant cytokine detected in inflammation and various cancers, on CXCL1 release by human A549 lung carcinoma epithelial cells. Methods: CXCL1 expression was determined by ELISA and RT-PCR. TNF- $\alpha$ signaling was examined by western blotting. Monocyte migration was assayed by a Transwell migration system. Results: TNF- $\alpha$ stimulated CXCL1 release and mRNA expression, and this release was inhibited by inhibitors of JNK, p38 MAPK, PI-3K/Akt and AP-1 transcription factor. TNF- $\alpha$ treatment was followed by JNK, p38 MAPK and PI3K/Akt activation. However, only the JNK inhibitor could reduce the CXCL1 mRNA level, suggesting that JNK is required mainly for CXCL1 mRNA synthesis, whereas p38 MAPK and PI-3K/Akt might be responsible for CXCL1 secretion. Dexamethasone (dex) and TGF- $\beta$ reduced CXCL1 secretion, with dex upregulating the expression of MAP kinase phosphatase-1 and TGF- $\beta$ causing smad2/3 activation and nuclear translocation. A functional analysis showed that the released CXCL1 enhanced monocyte migration and could be abolished by a CXCL1 neutralizing antibody and CXCR antagonist. Conclusion: We demonstrate that TNF- $\alpha$ induces CXCL1 expression through the JNK, p38 MAPK and PI-3K/Akt signaling pathways in human pulmonary epithelial cells.
\end{abstract}

Copyright (C) 2014 S. Karger AG, Basel

\section{Introduction}

Tumors are not merely masses of neoplastic cells but rather are complex tissues composed of both non-cellular (matrix proteins, cytokines, proteases and hormones) and cellular components (tumor-associated fibroblasts, capillary-associated cells and inflammatory cells) [1]. The soluble components, e.g., cytokines, chemokines and growth factors, may be derived from either neoplastic or non-neoplastic cells [2]. Tumor necrosis factor (TNF) is a multifunctional cytokine that plays important roles in diverse cellular 


\section{Cellular Physiology and Biochemistry}

Cell Physiol Biochem 2014;34:1373-1384

\begin{tabular}{l|l}
\hline DOI: $10.1159 / 000366344$ & (C) 2014 S. Karger AG, Basel
\end{tabular}

www.karger.com/cpb

Shieh et al.: TNF Signaling Pathways and CXCL1 Release

events, such as cell survival, proliferation, differentiation and death [3]. It is known that TNF plays a part in the pathogenesis of cancer [3] and atherosclerosis [4], and TNF can be detected in malignant and/or stromal cells in various cancers [5]. Clinically, elevated serum concentrations and increased TNF- $\alpha$ expression are present in various pre-neoplastic and malignant diseases [6].

CXCL1, also known as growth-related oncogene- $\alpha$ (GRO- $\alpha$ ), is a polypeptide that was initially isolated from human melanoma cells. CXCL1 is a member of the chemokine (chemotactic cytokines) family, which are small heparin-binding proteins that generally direct the movement of circulating leukocytes to sites of inflammation or injury [7]. CXCL1 is characterized as part of the glutamate-leucine-arginine (ELR) CXC chemokine family because it contains the ELR motif at the $\mathrm{N}$-terminus and because the first two conserved cysteine residues are separated by one amino acid $[8,9]$. CXCL1 can bind to the leukocyte receptors CXCR1 and CXCR2 [10]. ELR ${ }^{+}$chemokines are primarily chemotactic for endothelial cells and neutrophils, which are potent promoters of angiogenesis and inflammation $[11,12]$.

In a previous study, monocyte chemoattractant protein-1 (MCP-1) and CXCL1 were found to be upregulated by TNF in human airway epithelium and bronchoalveolar macrophages [13]. Various cancers, such as melanoma and breast, colon and ovarian cancer, express different chemokines and their receptors, which modulate leukocyte infiltration within the tumor microenvironment, tumor growth and metastasis [11]. In addition, it has been reported that interleukin (IL-17) augments the secretion of an array of angiogenic CXC chemokines, including CXCL1, $-5,-6$ and -8 , by three different non-small cell lung cancer (NSCLC) cell lines [14]. NSCLC biopsy specimens have high intratumoral concentrations of CXCR2 ligands, including CXCL1, -5 and $-8[15,16]$. CXCL1 and IL-18 were found to regulate stromal cell migration and K-ras mutant lung adenocarcinoma cell line (LKR-13) proliferation, and LKR-13 cell tumorigenicity required one or both of these proteins [17]. CXCL1 was also shown to play a pivotal role in thrombin-induced angiogenesis [18] and can modulate leukocyte infiltration within the tumor microenvironment, tumor growth and metastasis [11].

We previously found that TNF- $\alpha$, VEGF, lipopolysaccharide and thrombin treatment can lead to CXCL1 induction, and we also elucidated the possible mechanism of action of VEGF in causing CXCL1 release by A549 lung epithelial carcinoma cells [19]. Given that TNF- $\alpha$ is a potent proinflammatory cytokine and has been shown to be expressed in the lung tumor microenvironment [5], the effects of TNF- $\alpha$ on CXCL1 release in human A549 lung carcinoma epithelial cells were investigated in the present study. Our results revealed that TNF- $\alpha$ induces CXCL1 expression through transcriptional and nontranscriptional regulation involving JNK-, p38 MAPK- and PI-3K/Akt-dependent signaling pathways.

\section{Materials and Methods}

\section{Materials}

3-[4,5-Dimethylthiazol-2-yl]-2,5-diphenyltetrazolium bromide (MTT), PD98059, SB202190, SP600125, actinomycin D (Act. D) and cycloheximide (CHX) were purchased from Sigma Chemical Co. (St Louis, MO, USA). SB225002 was obtained from Cayman Chemicals (Ann Arbor, Michigan, USA). LY2228820 was purchased from Selleck Chemicals (Houston, TX, USA). Antibodies (Abs) raised against phosphoERK1/2 and Abs for total and phospho-smad 2/3 were obtained from Santa Cruz Biotechnology (Santa Cruz, CA, USA). Abs raised against total p38 MAPK, phospho-p38 MAPK, total JNK and phospho-JNK were obtained from Cell Signaling Technology, Inc. (Danvers, MA, USA). Human TNF- $\alpha$, CXCL1 neutralizing Ab and Abs against total p38 and ERK1/2 were obtained from R\&D systems, Inc. (MN, USA). Transforming growth factor (TGF)- $\beta$ was purchased from Invitrogen Life Technologies (Carlsbad, CA, USA). An Ab against $\alpha$-tubulin was purchased from Calbiochem EMD Bioscience Inc. (San Diego, CA, USA).

\section{Cell cultures}

Human A549 epithelial cells, a human pulmonary epithelial carcinoma cell line with type II alveolar epithelial cell differentiation, and U937 monocytes were purchased from Food Industry Research and 


\section{Cellular Physiology and Biochemistry}

Cell Physiol Biochem 2014;34:1373-1384

\begin{tabular}{l|l}
\hline DOI: $10.1159 / 000366344$ & (C) 2014 S. Karger AG, Basel
\end{tabular}

www.karger.com/cpb

Shieh et al.: TNF Signaling Pathways and CXCL1 Release

Development Institute (Hsinchu, Taiwan). The A549 cells were cultured in DMEM/Ham's F-12 nutrient mixture containing 10\% FBS (fetal bovine serum), penicillin (100 units $/ \mathrm{ml})$, streptomycin $(100 \mu \mathrm{g} / \mathrm{ml})$ and fungizone (250 ng/ml) (Invitrogen Life Technologies, Carlsbad, CA, USA). The U937 monocytes were cultured in RPMI 1640 medium with $2 \mathrm{mM}$ L-glutamine, $1.5 \mathrm{~g} / \mathrm{L}$ sodium bicarbonate, $4.5 \mathrm{~g} / \mathrm{L}$ glucose, $10 \mathrm{mM}$ HEPES, 1.0 mM sodium pyruvate and 10\% FBS.

\section{ELISA measurement of CXCL1 secreted into the culture medium}

CXCL1 release into the culture medium was determined using a human CXCL1 ELISA Development Kit (R\&D Systems, Inc, MN, USA) according to the manufacturer's protocol. Briefly, the culture medium was collected and centrifuged, and CXCL1 released into the culture medium was measured at $412 \mathrm{~nm}$. The intensity of the color is proportional to the amount of CXCL1 present in the well during incubation. The absolute concentration of CXCL1 in the cell culture medium was calculated from a standard curve.

\section{Cell viability and proliferation assay}

An MTT assay for cell viability/proliferation was performed as previously described [20]. Briefly, cells were incubated with $0.5 \mathrm{mg} / \mathrm{ml}$ MTT for $2 \mathrm{~h}$ at $37^{\circ} \mathrm{C}$. Formazan crystals resulting from MTT reduction were dissolved by adding DMSO. The absorbance of the supernatant was then measured spectrophotometrically using an ELISA reader at $550 \mathrm{~nm}$.

\section{CXCL1 reporter luciferase assay}

A CXCL1 luciferase reporter assay was performed as previously described [19]. Cells at approximately 80\% confluence in 6-well culture plates (Corning Inc., Tewksbury MA, USA) were transfected with 0.75 $\mu \mathrm{g}$ of total DNA using PolyJet ${ }^{\mathrm{TM}}$ in vitro DNA Transfection Reagent (SignaGen Lab, Rockville, MD, USA) for $18 \mathrm{~h}$ in medium, according to the manufacturer's protocol. All transient transfections included $0.375 \mu \mathrm{g}$ of CXCL1 reporter construct and the pSV- $\beta$-galactosidase control vector (Promega). The CXCL1 reporter firefly luciferase values were obtained by analyzing $1 \mathrm{ml}$ of purified cell extract according to the standard instructions provided by the Luciferase Kit (Promega) using a Wallac Victor 31420 multilabel counter (Perkin Elmer, Turku, Finland). $\beta$-Gal activity was used as an internal control and was determined using o-nitrophenyl- $\beta$-d-galactopyranoside as the substrate [21].

Cell lysate preparation and western blot analysis

Cell lysates were prepared as previously described [22]. Total proteins were separated by electrophoresis through SDS-polyacrylamide gels, electroblotted onto PVDF membranes and then probed using a primary $\mathrm{Ab}$. The immunoblots were developed using Immobilon Western Chemiluminescent HRP Substrate (EMD Millipore Corporation, Billerica, MA, USA). For some experiments, the membranes were stripped with striping buffer (62.5 mM Tris- $\mathrm{HCl}, \mathrm{pH}$ 6.7, 2\% SDS and $100 \mathrm{mM} \beta$-mercaptoethanol), washed and reprobed with Abs to examine the levels of $\alpha$-tubulin or the corresponding total proteins and then developed as described above.

Analysis of smad2/3 distribution and activation in cytosolic and nuclear fractions

After cells were treated with TGF- $\beta$, smad $2 / 3$ activation was assessed by analyzing expression in total cell lysates and distribution in cytosolic and nuclear fractions. To prepare cytosolic and nuclear fraction, cells were extracted using the Panomics Nuclear extraction kit (Panomics Inc., Redwood City, CA, USA) according to the manufacturer's protocol.

Reverse transcription-polymerase chain reaction (RT-PCR) analysis of CXCL1 mRNA expression

Oligonucleotide PCR primers targeting human CXCL1 and $\beta$-actin were synthesized. The forward and reverse primers for CXCL1 were 5'-GCCCAAACCGAAGTCATAGCC-3' and 5'-ATCCGCCAGCCTCTATCACA-3' and for $\beta$-actin were 5'-ATCATGTTTGAGACCTTCAA-3' and 5'-CATCTCTTGCTCGAAGTCCA-3', respectively. The procedure for the RT-PCR analysis of CXCL1 and $\beta$-actin has been previously described [19]. The amplification products were then analyzed by $2 \%$ agarose gel electrophoresis.

\section{Measurement of monocyte migration}

A monocyte migration assay was performed using a Transwell apparatus (8.0- $\mu \mathrm{m}$ pore size, Falcon). The lower chamber was seeded with/without A549 cells. After reaching 90\% confluence, cells were added with medium and recombinant CXCL1 (R\&D) or medium with TNF- $\alpha$. The upper chamber was coated 
Fig. 1. Effect of TNF- $\alpha$ on CXCL1 protein secretion and mRNA expression in human pulmonary epithelial cells. (A) Cells were treated with PBS or TNF- $\alpha$ for 16 h (left panel) or TNF- $\alpha$ (5 ng/ml) for the indicated time intervals (right panel). The culture media were collected and analyzed by ELISA. The data are mean \pm SEM (n=3). (B) Cells were treated with TNF- $\alpha$ (5 ng/ml) for 3 and $6 \mathrm{~h}$. At

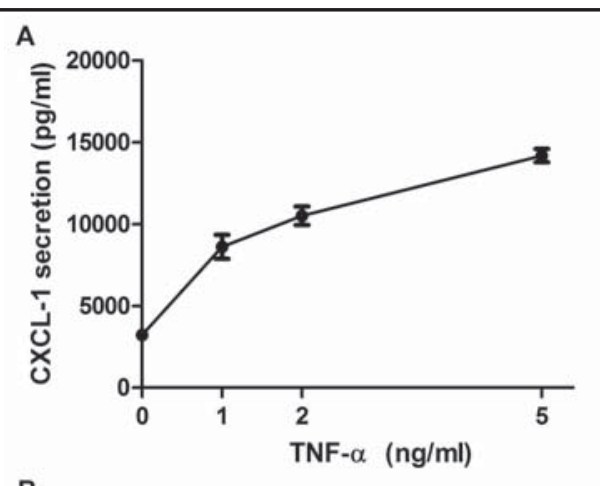

B
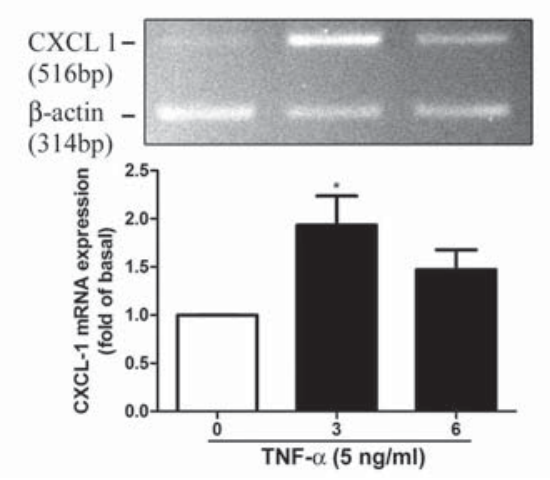

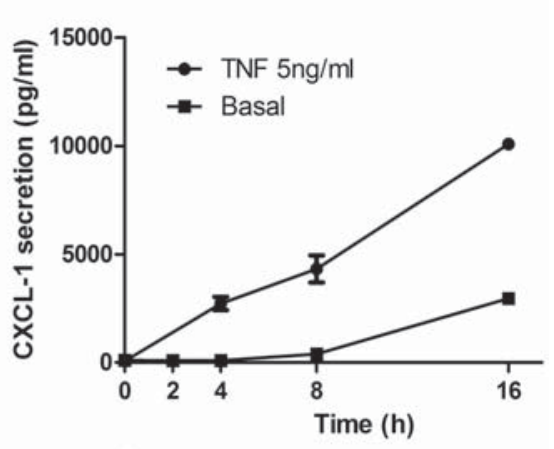

C

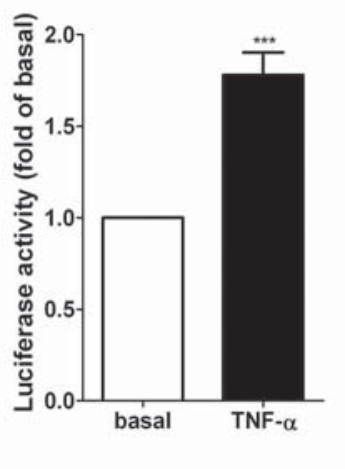

the end of incubation, total RNA was extracted, and CXCL1 and $\beta$-actin mRNA expression were analyzed by RT-PCR. Data from similar experiments were quantified by densitometry ( $n=3)$. (C) Cells were transfected with a CXCL1 promoter reporter and stimulated with vehicle or TNF- $\alpha(5 \mathrm{ng} / \mathrm{ml})$ for $16 \mathrm{~h}$. The data are the luciferase intensity ratio to $\beta$-gal activity and are expressed as fold of the basal level (vehicle treatment only) (n=3). ${ }^{*} P<0.05$, and ${ }^{* * *} P<0.001$ versus the basal condition.

with gelatin $(10 \mu \mathrm{g} / \mathrm{ml})$ and loaded with U937 monocytes $\left(2.5 \times 10^{5}\right.$ cells $\left./ \mathrm{ml}\right)$. After assembling the lower chamber, the apparatus was incubated at $37^{\circ} \mathrm{C}$ for $16 \mathrm{~h}$. All nonmigrant monocytes were removed with a cotton swab, and the migrated monocytes were fixed and stained with $0.5 \%$ toluidine blue in $4 \%$ PAF. Migration was quantified by counting the number of stained cells per $\times 100$ field (high power field, HPF) under a phase-contrast microscope (Nikon Eclipse Ti-S, Japan); the cells were photographed.

\section{Statistical analysis}

The data are expressed as the mean \pm standard error mean (SEM). A comparison of the means of two groups of data was performed by using the unpaired, two-tailed Student's $t$ test.

\section{Results}

TNF- $\alpha$ induces CXCL1 release in human A549 pulmonary epithelial cells

The concentration- and time-dependent effects of TNF- $\alpha$ on CXCL1 release were examined in human pulmonary epithelial cells. As shown in Fig. 1A, TNF- $\alpha$ enhanced CXCL1 release in a concentration-dependent manner, with $1 \mathrm{ng} / \mathrm{ml}$ of TNF- $\alpha$ being sufficient to cause CXCL1 release (left panel). Moreover, TNF- $\alpha$ induced CXCL1 release in a time-dependent manner, and a significant increase could be observed after a short (4-h) incubation (Fig. 1A, right panel).

To further examine whether TNF- $\alpha$ induces CXCL1 mRNA expression, cells were treated with TNF- $\alpha$ for 3 and $6 \mathrm{~h}$, and CXCL1 and $\beta$-actin mRNA expression was evaluated by RT-PCR. As shown in Fig. 1B, CXCL1 mRNA was markedly upregulated by TNF- $\alpha$ at $3 \mathrm{~h}$ but slightly declined at $6 \mathrm{~h}$, whereas $\beta$-actin mRNA expression remained unaffected. This result indicated that TNF- $\alpha$ might affect CXCL1 expression through transcriptional regulation. To test this 


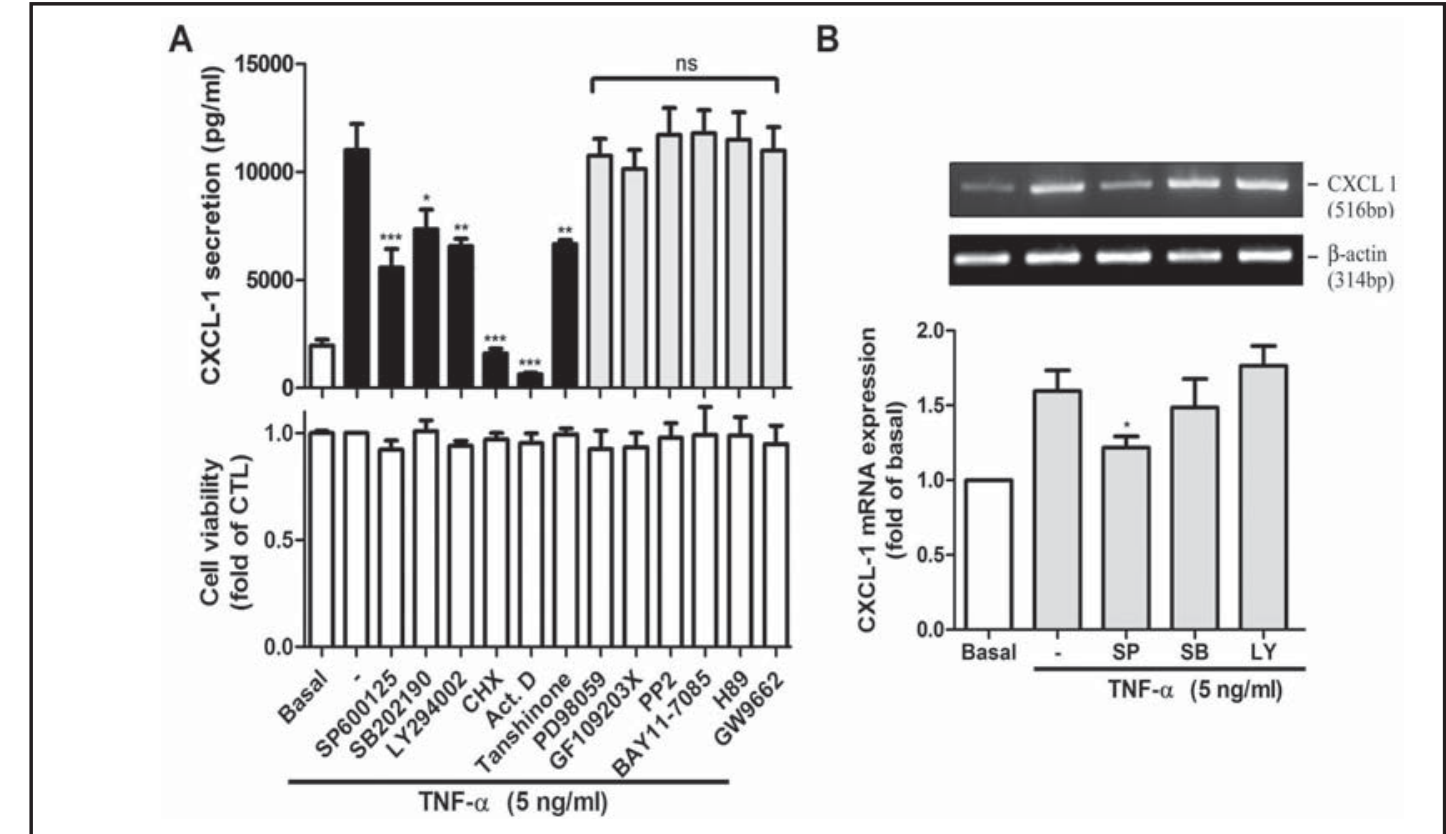

\section{B}

Fig. 2. Effect of signaling inhibitors on TNF- $\alpha$-induced CXCL1 secretion and mRNA levels in human pulmonary epithelial cells. (A) Cells were pretreated with various inhibitors for $1 \mathrm{~h}$, followed by PBS (basal) or TNF- $\alpha$ for $16 \mathrm{~h}$. CXCL1 in the culture medium was analyzed by ELISA (upper panel), and the remaining adherent cells were examined for cell viability by an MTT assay (lower panel). The data are the mean \pm SEM (n=3-5). (-): TNF- $\alpha$ control. ${ }^{*} P<0.05,{ }^{* *} P<0.01,{ }^{* * *} P<0.001$ versus TNF- $\alpha$ control. (B) Cells were pretreated with SP600125 (SP), SB202190 (SB) or LY294002 (LY) (10 $\mu \mathrm{M}$ each) for $1 \mathrm{~h}$, followed by stimulation with TNF- $\alpha$ for $3 \mathrm{~h}$. Total RNA was extracted, and CXCL1 and $\beta$-actin mRNA expression were analyzed by RT-PCR. The data are the mean \pm SEM $(n=3) .{ }^{*} P<0.05$ versus TNF- $\alpha$ control.

hypothesis, cells were transfected with a human CXCL1 promoter reporter construct, and a luciferase assay was performed. As presented in Fig. 1C, TNF- $\alpha$ treatment significantly enhanced luciferase activity by approximately 1.8 -fold in cells, suggesting an increase in cxcl1 transcription by TNF- $\alpha$.

\section{Effect of signaling inhibitors on TNF- $\alpha$-induced CXCL1 expression}

Next, we investigated the possible signaling pathways involved in the induction of CXCL1 expression by TNF- $\alpha$; several signaling inhibitors targeting MAPKs, PI-3K, protein kinases, the NF- $\kappa B$ signaling pathway, transcription and protein translation were used in this assay. Fig. 2A shows that a JNK inhibitor (SP600125), p38 MAPK inhibitor (SB202190), PI-3K inhibitor (LY294002), AP-1 transcription factor inhibitor (tanshinone IIA), protein translation inhibitor (cycloheximide) and DNA transcription inhibitor (Act. D) significantly inhibited CXCL1 release due to TNF- $\alpha$. In contrast, other signaling inhibitors, including a MAPKK inhibitor (PD98059), PKC inhibitor (GF109203X), src inhibitor (PP2), NF-кB inhibitor (BAY117085), PKA inhibitor (H-89) and PPAR $\gamma$ inhibitor (GW9662) (upper panel), had no effect. Furthermore, the inhibition was not caused by a decrease in cell viability, as demonstrated by the MTT assay (Fig. 2A, lower panel).

We next examined whether the JNK inhibitor (SP600125), p38 MAPK inhibitor (SB202190) and PI-3K inhibitor (LY294002) affected TNF- $\alpha$-induced CXCL1 mRNA expression. Surprisingly, only SP600125 was found to repress the TNF- $\alpha$-induced expression of CXCL1 mRNA (Fig. 2B). Therefore, the results suggested that JNK activation might mediate TNF- $\alpha$-induced CXCL1 mRNA transcription, whereas the p38 MAPK and PI-3K pathways might affect CXCL1 secretion into the extracellular space. 


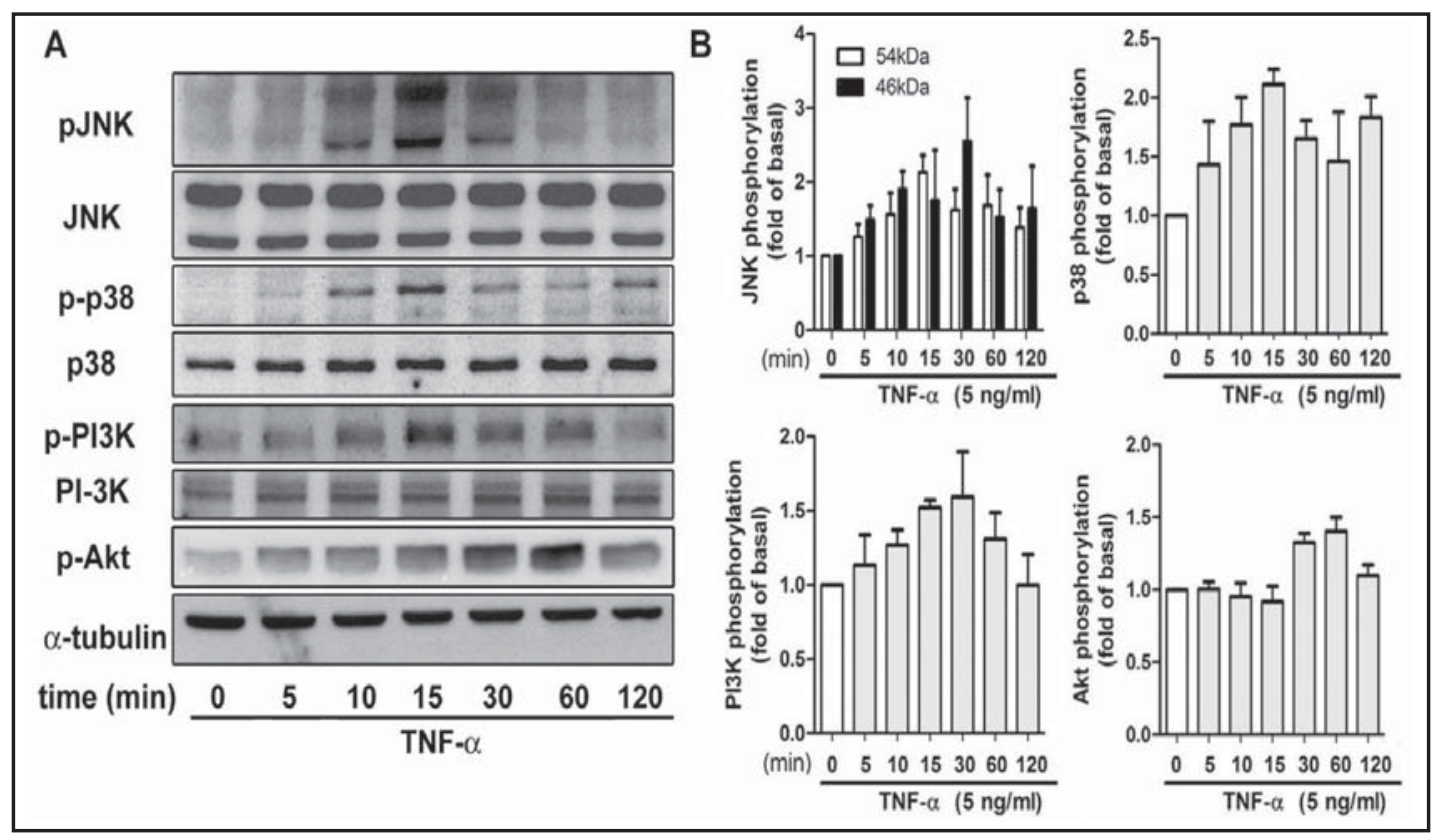

Fig. 3. Effect of TNF- $\alpha$ on MAPK, PI-3K and Akt activation in human pulmonary epithelial cells. Cells were treated with TNF- $\alpha(5 \mathrm{ng} / \mathrm{ml})$ for the indicated time intervals. Cell lysates were collected, and the activation of the cellular kinases was analyzed by western blotting. A representative blot is shown, and similar results were quantified by densitometry $(n=3-4)$.

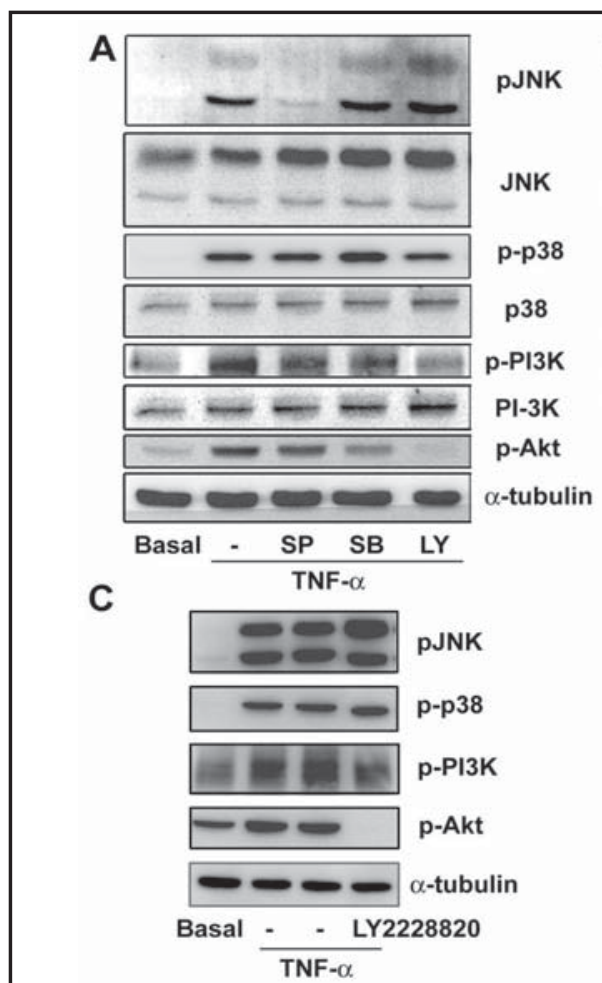

B
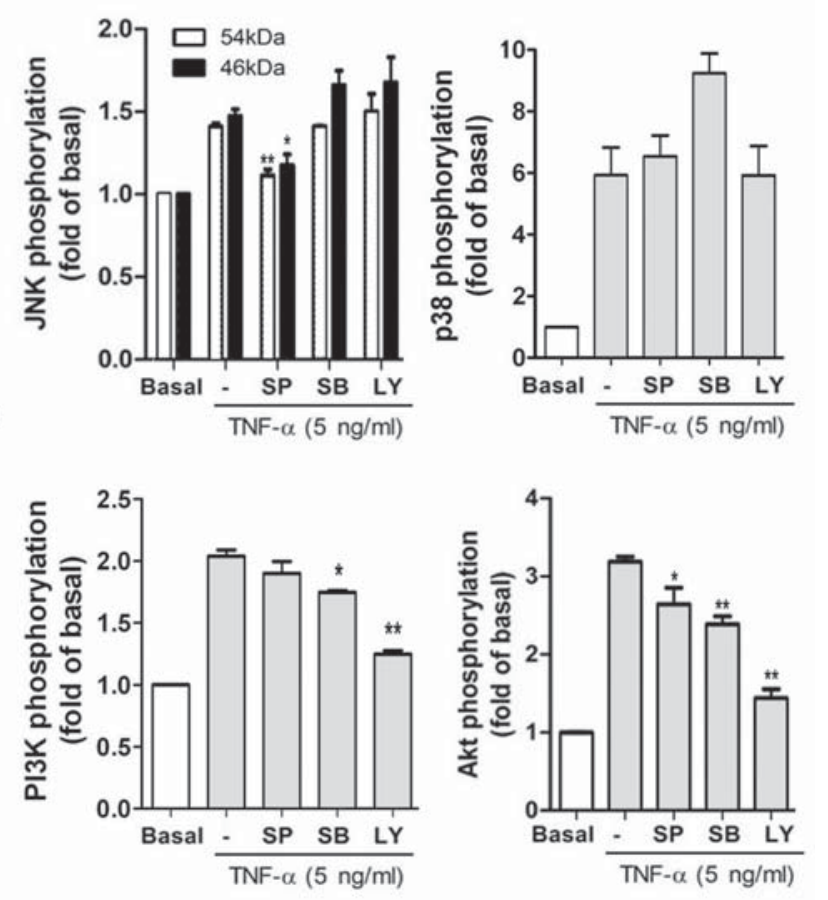

Fig. 4. Activation context of JNK, p38 MAPK and PI-3K/Akt in pulmonary epithelial cells due to TNF- $\alpha$ stimulation. Cells were pretreated with SP600125 (SP), SB202190 (SB) or LY294002 (LY) (10 $\mu$ M each) for 1 $\mathrm{h}$, followed by stimulation with $5 \mathrm{ng} / \mathrm{ml}$ of TNF- $\alpha$ for $15 \mathrm{~min}$. (A) A representative blot is shown. (B) Similar results were quantitated by densitometry and are expressed as the mean \pm SEM $(n=3-4) .{ }^{*} P<0.05,{ }^{* *} P<0.01$ versus TNF- $\alpha$ alone. (C) Effect of LY2228820 (10 $\mu \mathrm{M})$ on TNF- $\alpha$-induced JNK, p38 MAPK and PI-3k/Akt activation. 
Fig. 5. Effect of dex on TNF- $\alpha$-induced CXCL1 secretion and signaling in human pulmonary epithelial cells. (A) Cells were treated with TNF- $\alpha$ in the absence or presence of dex for 16 h. CXCL1 in the culture medium was analyzed by ELISA. (B) Cells were pretreated with dex (500 $\mathrm{nM}$ ) for $30 \mathrm{~min}$, followed by stimulation with TNF- $\alpha$ (5 ng/ $\mathrm{ml}$ ) for $30 \mathrm{~min}$. MKP1 expression was determined by RT-PCR. (C) Cells were treated with dex as described in (B), except they were stimulated with TNF- $\alpha$ for 15 min. JNK
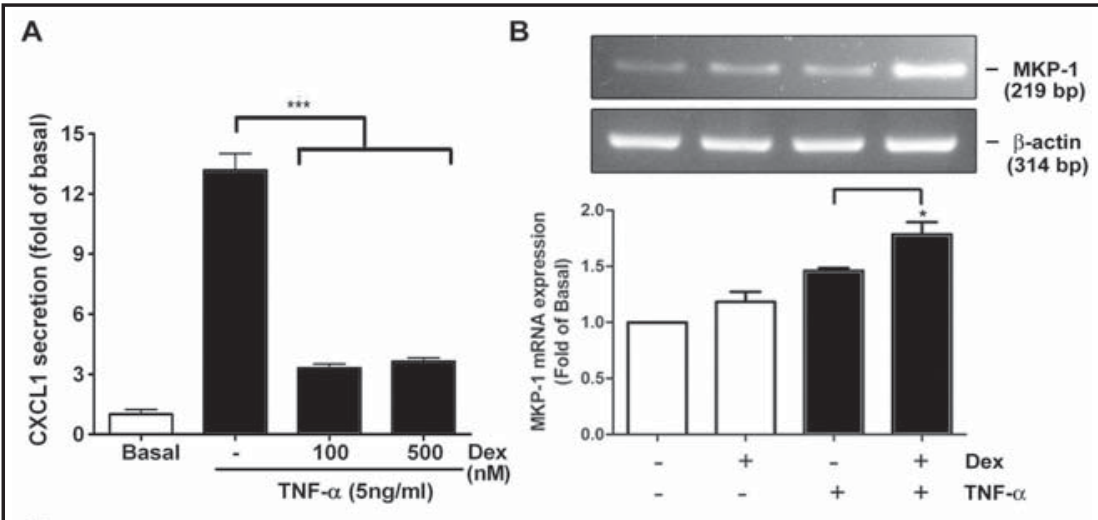

C
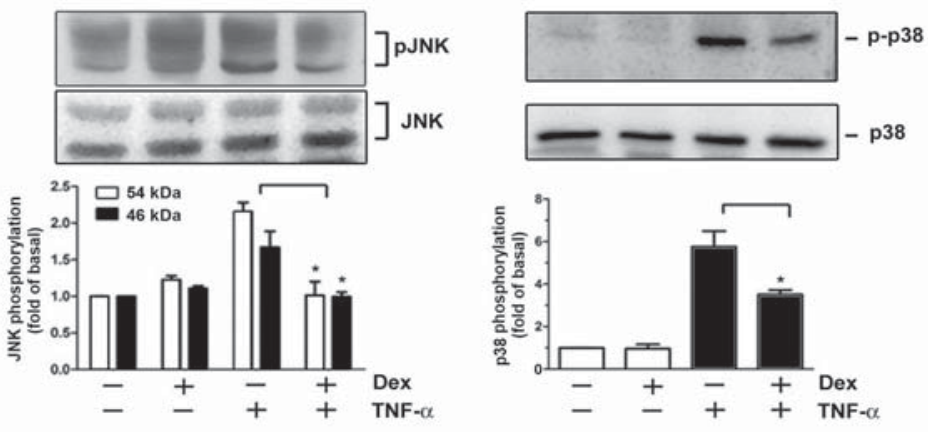
and p38 MAPK activation and expression were analyzed by western blotting. The data are the mean \pm SEM $(\mathrm{n}=3) .{ }^{*} \mathrm{P}<0.05$ versus TNF- $\alpha$ alone.

TNF- $\alpha$ treatment leads to the activation of JNK, p38 MAPK, PI-3K and Akt

As we found that the JNK, p38 MAPK and PI-3K inhibitors reduced TNF- $\alpha$-induced CXCL1 release, we next tested whether TNF- $\alpha$ could directly activate related signaling pathways in pulmonary epithelial cells. Fig. 3 shows that TNF- $\alpha$ markedly induced the activation (phosphorylation) of JNK, p38 MAPK, PI-3K and Akt in these cells. The activation occurred in a time-dependent manner, in which JNK and p38 MAPK phosphorylation was apparent at 10 30 min but returned to the basal level at $60 \mathrm{~min}$. However, PI-3K and Akt activation was more obvious at 15 60 min, suggesting that these factors are possibly activated downstream of JNK and/or p38 MAPK.

The activation context of these kinases related to TNF- $\alpha$-induced CXCL1 release was then analyzed by western blotting. The effectiveness of SP600125, SB201290 and LY294002 on their respective kinases is shown in Fig. 4A and B. We observed that SB202190 did not affect p38 MAPK phosphorylation, even though its specificity and inhibitory ability on p38 MAPK have been demonstrated by us and others $[23,24]$. Under these conditions, we observed that both JNK and p38 MAPK inhibitors markedly inhibited TNF- $\alpha$-induced Akt activation and slightly affected PI-3K activation. The JNK inhibitor did not affect p38 MAPK activation and vice versa. Moreover, the PI-3K inhibitor (LY294002) inhibited both PI-3K and Akt activation but had no effect on JNK and p38 activation (Fig. 4A and B). The inhibitory effect of SB201290 on PI-3K and Akt was verified by using another p38 MAPK inhibitor, LY2228820. Fig. 4C shows that LY2228820 also did not affect the activation of p38 MAPK but it did reduce PI-3K and Akt activation. Taken together, these findings suggested that TNF- $\alpha$ can activate JNK and p38 MAPK independently and that both can then activate PI-3K and Akt.

Effect of dexamethasone (dex) and TGF- $\beta$ on TNF- $\alpha$-induced CXCL1 production

A previous study has shown that a clinically used corticosteroid, dex, can inhibit TNF$\alpha$-induced CXCL1 secretion by tracheal smooth muscle cells through the induction of MAPK phosphatase-1 (MKP-1) expression, leading to the inactivation of JNK, which is required for 

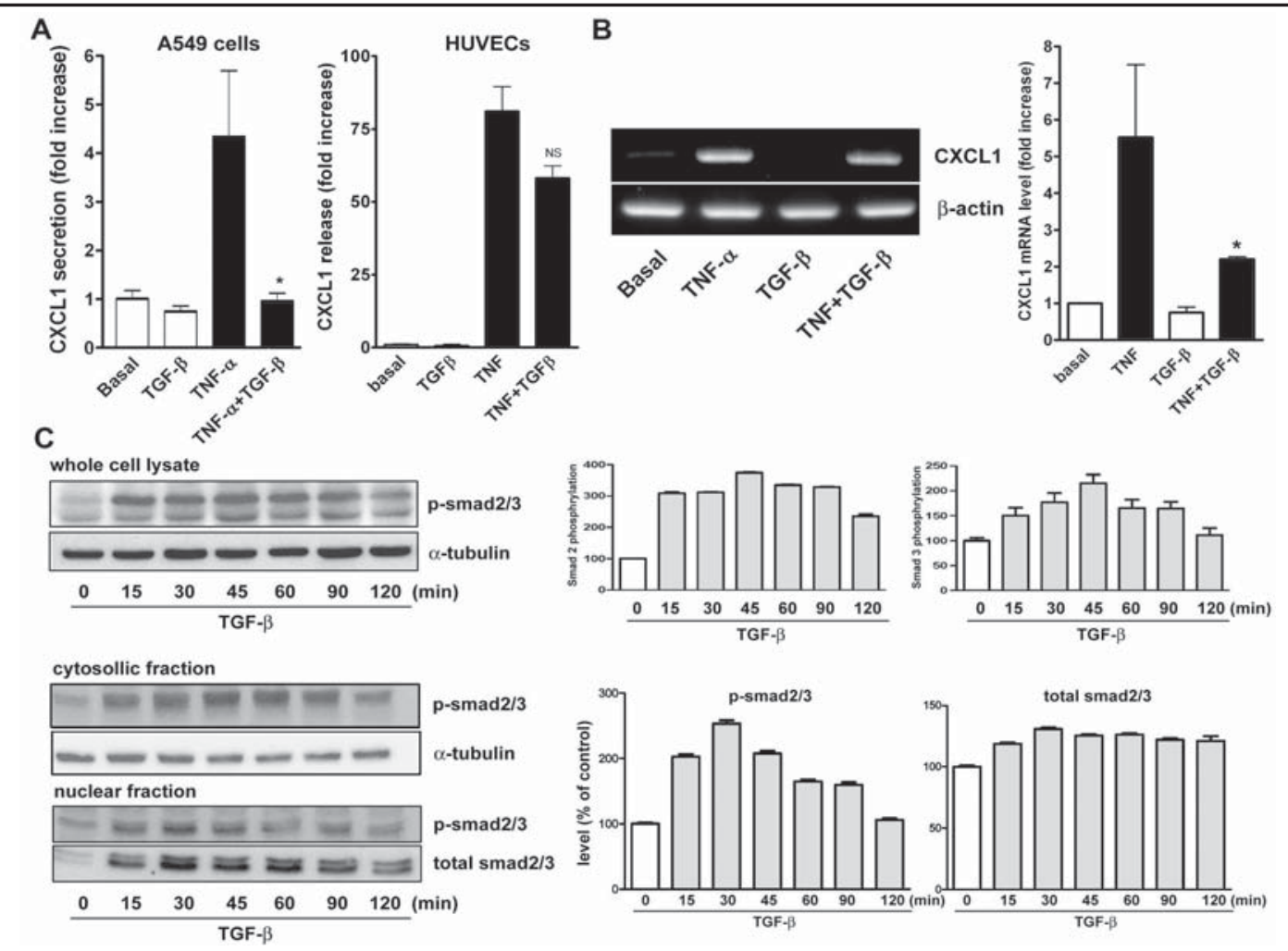

Fig. 6. Effect of TGF- $\beta$ on CXCL1 expression and cellular signaling. (A and B) Effect of TGF- $\beta$ on TNF- $\alpha$ induced CXCL1 expression. A549 cells and HUVECs were treated with PBS (basal) or TNF- $\alpha$ in the absence or presence of TGF- $\beta$ ( $5 \mathrm{ng} / \mathrm{ml}$ ) for $16 \mathrm{~h}$ and $6 \mathrm{~h}$, respectively. CXCL1 in the culture medium was analyzed by ELISA; total RNA from the remaining cells was extracted, and CXCL1 mRNA was analyzed by RT-PCR. Data from similar experiments were quantified ( $n=3-4)$. (C) Effect of TGF- $\beta$ on cellular signaling in lung epithelial cells. Cells were treated with TGF- $\beta$ ( $5 \mathrm{ng} / \mathrm{ml}$ ) for the indicated time intervals. Smad2/3 phosphorylation and expression in whole-cell lysates (upper panels) and subcellular fractions (lower panels) were analyzed by western blotting $(n=3)$. NS: non significant.

CXCL1 transcription [25]. In addition, the disruption of TGF- $\beta$ homeostasis occurs in several human cancers, such as lung cancer [26-28]. Therefore, we tested whether dex and TGF- $\beta$ affect TNF- $\alpha$-induced CXCL1 release. As shown in Fig. 5A, dex (100 and $500 \mathrm{nM}$ ) markedly inhibited TNF- $\alpha$-induced CXCL1 secretion by epithelial cells. Dex slightly induced MKP-1 expression under the basal unstimulated condition and notably increased MKP-1 expression in TNF- $\alpha$-treated cells (Fig. 5B). Concomitantly, this was accompanied by the observation that dex reduced TNF- $\alpha$-induced JNK and p38 MAPK phosphorylation (Fig. 5C).

Next, we examined whether TGF- $\beta$ affects TNF- $\alpha$-induced CXCL1 expression. As shown in Fig. 6A, we found that TGF- $\beta$ alone did not cause any inhibition under the basal condition but did significantly inhibit TNF- $\alpha$-induced CXCL1 secretion by A549 cells (left panel). In contrast, TGF- $\beta$ only slightly affected CXCL1 release from human umbilical vein endothelial cells (HUVECs) (Fig. 6A, right panel). The RT-PCR analysis indicated that CXCL1 mRNA was also decreased when the cells were treated with TGF- $\beta$ (Fig. 6B), suggesting the involvement of the transcriptional downregulation of CXCL1. It has been reported that all TGF ligands bind to type I and type II receptors, which interact with other proteins, subsequently leading to smad homo- and hetero-oligomerization and mediating the transactivation potential of nuclear smad complexes [29]. Thus, we next examined whether TGF- $\beta$ stimulates smad activation in cells. As shown in Fig. 6C, smad2/3 phosphorylation in whole-cell lysates and smad $2 / 3$ translocation into the nucleus were observed in the nuclear fraction when the cells 
Fig. 7. Effect of CXCL1 on pulmonary epithelial cell growth and monocyte migration. (A) Exogenous CXCL1 was added to pulmonary epithelial cells for $16 \mathrm{~h}$, and cell growth was analyzed by an MTT assay. The data are the mean \pm SEM $(n=3)$. (B) The upper Transwell insert was seeded with monocytes and assembled with the lower chamber filled with a medium containing recombinant CXCL1; the migrated monocytes were photographed and counted. The data are the mean \pm SEM $(\mathrm{n}=2-3) .{ }^{* * *} \mathrm{P}<0.001$ versus the basal condition. (C and D) The upper Transwell insert was seeded with monocytes and assembled with the lower

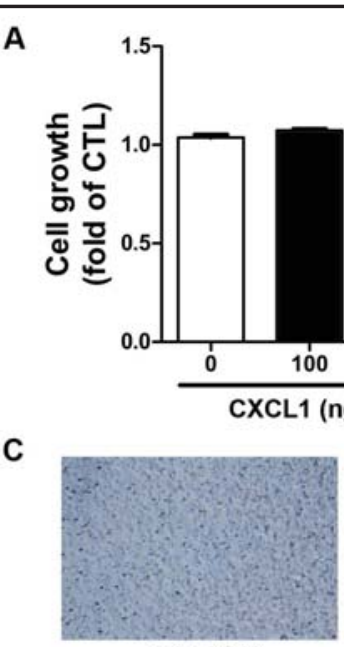

w/o A549

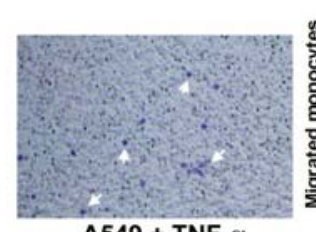

A549 + TNF $-\alpha$
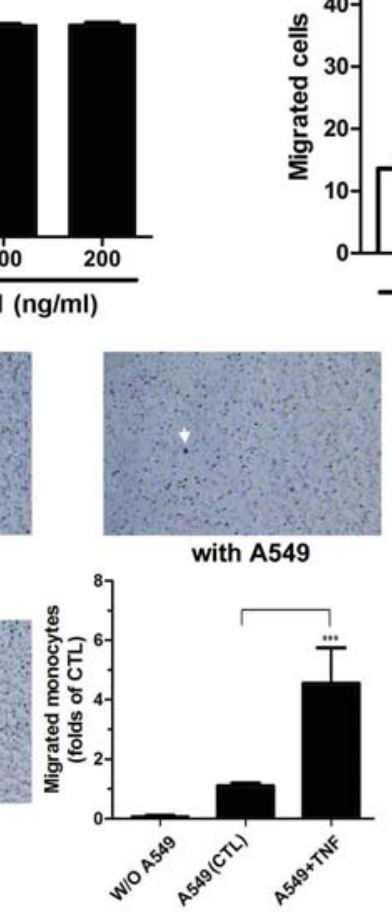

B

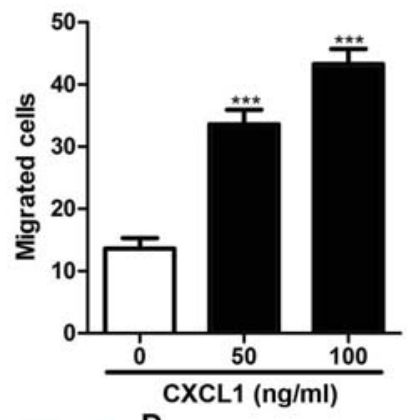

D

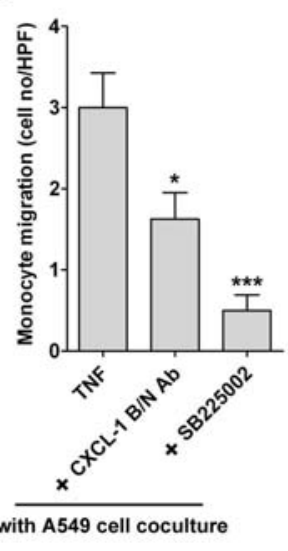

chamber seeded with/without lung epithelial cells in the presence of TNF- $\alpha(5 \mathrm{ng} / \mathrm{ml})$ and SB225002 (SB, $0.5 \mu \mathrm{M})$ or CXCL1 B/N Ab $(10 \mu \mathrm{g} / \mathrm{ml})$. After incubation for $16 \mathrm{~h}$, the migrated monocytes were fixed and counted by microscopy $(n=2-3)$.

were challenged with TGF- $\beta$, indicating that TGF- $\beta$ induces nuclear signaling within cells, which might affect cxcl1 transcription.

\section{Effect of CXCL1 on epithelial cell proliferation and monocyte migration}

We next evaluated the functional effect of CXCL1 on epithelial cell proliferation and monocyte migration. As shown in Fig. 7A, exogenous CXCL1 did not affect the proliferation of A549 epithelial cells, but it did induce a robust increase in the number of migrated monocytes when CXCL1 was added to the lower chamber of the Transwell migration system (Fig. 7B). The role of the CXCL1 released by epithelial cells in recruiting monocytes was further demonstrated using the same migration system, except in the absence or presence of epithelial cells and TNF- $\alpha$ in the lower chamber. In this coculture system, TNF- $\alpha$ alone could not cause monocyte migration (data not shown); however, it did cause monocyte migration of approximately 5 -fold when the epithelial cells were cocultured and stimulated with TNF- $\alpha$ in the lower chamber (Fig. 7C). This migration was significantly reduced by a CXCL1 blocking/ neutralizing $\mathrm{Ab}(\mathrm{B} / \mathrm{N} \mathrm{Ab}$ ) and SB225002 (a CXCR2 antagonist) (Fig. 7D), suggesting that the CXCL1 released by pulmonary epithelial cells acts as a chemoattractant for recruiting monocytes.

\section{Discussion}

TNF- $\alpha$ is a potent immunoregulatory cytokine that may have various effects on the growth and death of normal and cancerous lung cells [30, 31]. In this study, the TNF- $\alpha$ mechanism of action on CXCL1 release in human lung carcinoma epithelial cells was investigated. We show that TNF- $\alpha$ induced CXCL1 release through JNK-, p38 MAPK- and PI-3K/Akt- 
Fig. 8. Scheme of TNF- $\alpha$ signaling with regard to enhancing CXCL1 release by human pulmonary epithelial cells. TNF- $\alpha$ simultaneously induces JNK and p38 tion of the AP-1 transcription factor and for driving the CXCL1 transcription machinery, whereas JNK and p38 MAPK are both responsible for PI-3K and Akt activation, which may be required for CXCL1 release. The possible mechanism for the involvement of dexamethasone (dex) and TGF- $\beta$ in CXCL1 release is also indicated. Solid arrows: this study. Dashed arrows: suggestive. MAPK activation. JNK is responsible for the activa-

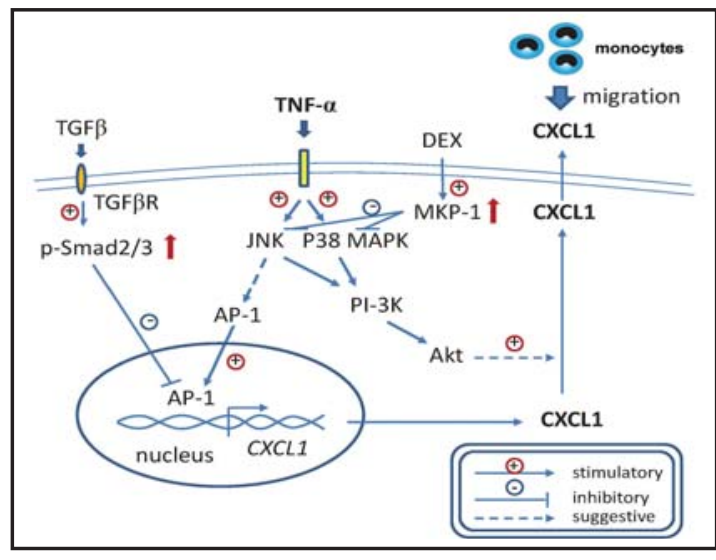

dependent pathways. Although CXCL1 itself did not cause epithelial cell proliferation, it did promote monocyte migration (Fig. 7A and B). Moreover, pulmonary epithelial cells treated with TNF- $\alpha$ significantly induced monocyte migration (Fig. 7C and D), suggesting that the CXCL1 released by epithelial cells due to TNF- $\alpha$ stimulation is able to functionally attract monocytes to the lung cancer microenvironment.

Based on our findings, we suggest that CXCL1 induction by TNF- $\alpha$ in pulmonary epithelial cells involves transcriptional regulation. Several lines of evidence support this hypothesis. First, TNF- $\alpha$ enhanced both CXCL1 mRNA transcription (Fig. 1B) and CXCL1 Luc reporter activity (Fig. 1C). Secondly, tanshinone IIA (an inhibitor of the AP-1 transcription factor), and gene transcription (act. D) and protein translation (CHX) inhibitors could attenuate TNF- $\alpha$-induced CXCL1 release (Fig. 2A). Past studies have shown that NF- $\kappa$ B mediates IL-1/ TNF- $\alpha$ induction of CXCL1 in human fibroblasts [32] and that protein kinase C (PKC) mediates TNF- $\alpha$ - and thrombin-induced CXC chemokine expression in human vascular endothelial cells $[33,34]$. However, in this study, we show that an NF- $\kappa B$ inhibitor (BAY117085), a general PKC inhibitor (GF109203X) and a PKA inhibitor (H-89) did not affect TNF- $\alpha$-induced CXCL1 release (Fig. 2A), indicating that the induction process did not involve the activation of NF- $\kappa$ B, PKA and PKCs.

Regarding which cellular kinases are responsible for TNF- $\alpha$-induced CXCL1 expression in epithelial cells, we suggest the involvement of JNK, p38 MAPK, PI-3K/Akt and AP-1, as largely demonstrated by the observation that the corresponding inhibitors were capable of inhibiting CXCL1 release (Fig. 2A). However, only the JNK inhibitor, and not the p38 MAPK and PI-3K inhibitors, reduced TNF- $\alpha$-induced CXCL1 mRNA expression (Fig. 2B), suggesting that JNK mainly participates in transcriptional regulation, whereas p38 MAPK and PI-3K/ Akt might be mainly responsible for cellular CXCL1 release. In line with this observation, we found that TNF- $\alpha$ could directly and notably activate JNK, p38 MAPK, PI-3K and Akt (Fig. $3)$. In this regard, the regulatory mechanism by TNF- $\alpha$ in A549 cells is similar to that observed in human umbilical vein endothelial cells (HUVECs) treated with TNF- $\alpha$ [24]. However, there are also some differences between these two cell types in response to TNF- $\alpha$ and other stimulators, revealing an interesting cell type-specific feature. First, VEGF and TNF- $\alpha$ are the most potent stimulators of A549 epithelial cells, whereas LPS and TNF- $\alpha$ are stimulators of HUVECs $[19,24]$. Second, the steroid dexamethasone markedly inhibited TNF- $\alpha-$ induced CXCL1 release by A549 epithelial cells, though it failed to affect CXCL1 release by HUVECs (Fig. 5 and [24]). Third, TGF- $\beta$ affected CXCL1 release by A549 epithelial cells but only slightly affected CXCL1 in HUVECs (Fig. 6). Interestingly, the regulatory mechanisms between TNF- $\alpha$ - and VEGF-induced CXCL1 expression are different in A549 epithelial cells [19]. CXCL1 release by A549 cells due to VEGF depends on VEGFR, JNK and PI-3K/Akt activation and is independent of the p38 MAPK and AP-1 TF pathways $[19,24]$. Collectively, these results demonstrate that JNK and PI-3K/Akt signaling might be a common pathway for cellular CXCL1 production, whereas other signaling pathway might depend on the type of stimulator used. 


\section{Cellular Physiology and Biochemistry}

Cell Physiol Biochem 2014;34:1373-1384

\begin{tabular}{l|l}
\hline DOI: $10.1159 / 000366344$ & (C) 2014 S. Karger AG, Basel
\end{tabular}

\begin{tabular}{l|l} 
Publisned online: Uctober 02, 2014 & www.karger.com/cpb
\end{tabular}

Shieh et al.: TNF Signaling Pathways and CXCL1 Release

We also show that dex inhibits TNF- $\alpha$-induced CXCL1 expression. This inhibitory effect mainly resulted from the fact that dex induced MKP-1 expression in the presence of TNF- $\alpha$, dephosphorylating JNK and p38 MAPK activated by TNF- $\alpha$ in epithelial cells (Fig. 5). However, it appears that TGF- $\beta$ inhibited TNF- $\alpha$-induced CXCL1 release more than CXCL1 mRNA expression (Fig. 6). As TGF- $\beta$ markedly resulted in smad $2 / 3$ phosphorylation and translocation into the nucleus, we suggest that TGF- $\beta$ mainly interferes with $c x c l 1$ transcription. However, whether mechanisms other than transcriptional regulation by TGF- $\beta$ are involved in this process remains to be investigated in future studies.

In conclusion, we demonstrate here that TNF- $\alpha$ can induce CXCL1 mRNA and protein expression in human pulmonary epithelial cells through JNK, p38 MAPK and PI-3K/Akt-dependent pathways. Fig. 8 illustrates that TNF- $\alpha$ stimulation simultaneously causes the activation of JNK and p38 MAPK. JNK and AP1 are required for CXCL1 mRNA transcription, whereas the JNK, p38 MAPK and PI-3K/Akt pathways may be important for controlling cellular CXCL1 release. Furthermore, CXCL1 expression can be reduced by TGF- $\beta$ and dex. The CXCL1 secreted by epithelial cells functions as a chemoattractant for recruiting monocytes in this microenvironment.

\section{Abbreviations}

Dex (dexamethasone); JNK (c-Jun N-terminal kinase); GRO- $\alpha$ (growth-related oncogene- $\alpha$ ); MAPK (mitogen-activated protein kinase); MAPKK (mitogen-activated protein kinase kinase); MKP-1 (MAPK phosphatase-1); PI-3K (phosphoinositide-3 kinase); TGF- $\beta$ (transforming growth factor- $\beta$ ); TNF- $\alpha$ (tumor necrosis factor- $\alpha$ ).

\section{Acknowledgements}

This work was supported by research grants from the National Science Council (Taipei, Taiwan) and Chi-Mei Medical Center (Tainan, Taiwan).

\section{References}

1 Sica A, Bronte V: Altered macrophage differentiation and immune dysfunction in tumor development. J Clin Invest 2007;117:1155-1166.

2 Ruiter D, Bogenrieder T, Elder D, Herlyn M: Melanoma-stroma interactions: Structural and functional aspects. Lancet Oncol 2002;3:35-43.

-3 Wang X, Lin Y: Tumor necrosis factor and cancer, buddies or foes[quest]. Acta Pharmacol Sin 2008;29:12751288.

-4 DePalma RG, Hayes VW, Cafferata HT, Mohammadpour HA, Chow BK, Zacharski LR, Hall MR: Cytokine signatures in atherosclerotic claudicants. J Surg Res2003;111:215-221.

5 Balkwill F, Mantovani A: Inflammation and cancer: Back to virchow? Lancet 2001;357:539-545.

6 Szlosarek P, Charles KA, Balkwill FR: Tumour necrosis factor- $\alpha$ as a tumour promoter. Eur J Cancer 2006;42:745750.

7 Charo IF, Ransohoff RM: The many roles of chemokines and chemokine receptors in inflammation. N Engl J Med 2006;354:610-621.

8 Feng G, Ohmori Y, Chang P-L: Production of chemokine cxcl1/kc by okadaic acid through the nuclear factor-kb pathway. Carcinogenesis 2005;27:43-52.

- Zlotnik A, Yoshie 0: Chemokines: A new classification system and their role in immunity. Immunity 2000;12:121-127.

10 Baggiolini M: Chemokines in pathology and medicine. J Int Med 2001;250:91-104.

11 Nannuru KC, Singh S, Singh RK: Chemokines and metastasis the tumor microenvironment; in Bagley RG (ed): Springer New York, 2010, pp 601-631.

12 Scapini P, Morini M, Tecchio C, Minghelli S, Di Carlo E, Tanghetti E, Albini A, Lowell C, Berton G, Noonan DM, Cassatella MA: Cxcl1/macrophage inflammatory protein-2-induced angiogenesis in vivo is mediated by neutrophilderived vascular endothelial growth factor-a. J Immunol 2004;172:5034-5040. 


\section{Cellular Physiology and Biochemistry}

Cell Physiol Biochem 2014;34:1373-1384

\begin{tabular}{l|l}
\hline DOI: $10.1159 / 000366344$ & (C) 2014 S. Karger AG, Basel
\end{tabular}

Published onine: October 02, $2014 \quad$ www.karger.com/cpb

Shieh et al.: TNF Signaling Pathways and CXCL1 Release

13 Becker S, Quay J, Koren HS, Haskill JS: Constitutive and stimulated mcp-1, gro alpha, beta, and gamma expression in human airway epithelium and bronchoalveolar macrophages. Am J Physiol - Lung Cell Mol Physiol 1994;266:L278-L286.

-14 Numasaki M, Watanabe M, Suzuki T, Takahashi H, Nakamura A, McAllister F, Hishinuma T, Goto J, Lotze MT, Kolls JK, Sasaki H: Il-17 enhances the net angiogenic activity and in vivo growth of human non-small cell lung cancer in scid mice through promoting cxcr-2-dependent angiogenesis. J Immunol 2005;175:6177-6189.

-15 Huang M, Wang J, Lee P, Sharma S, Mao JT, Meissner H, Uyemura K, Modlin R, Wollman J, Dubinett SM: Human non-small cell lung cancer cells express a type 2 cytokine pattern. Cancer Res 1995;55:3847-3853.

16 Arenberg DA, Keane MP, DiGiovine B, Kunkel SL, Morris SB, Xue YY, Burdick MD, Glass MC, Iannettoni MD, Strieter RM: Epithelial-neutrophil activating peptide (ena-78) is an important angiogenic factor in non-small cell lung cancer. J Clin Invest 1998;102:465-472.

17 Zhong L, Roybal J, Chaerkady R, Zhang W, Choi K, Alvarez CA, Tran H, Creighton CJ, Yan S, Strieter RM, Pandey A, Kurie JM: Identification of secreted proteins that mediate cell-cell interactions in an in vitro model of the lung cancer microenvironment. Cancer Res 2008;68:7237-7245.

18 Caunt M, Hu L, Tang T, Brooks PC, Ibrahim S, Karpatkin S: Growth-regulated oncogene is pivotal in thrombininduced angiogenesis. Cancer Res2006;66:4125-4132.

19 Lo H-M, Shieh J-M, Chen C-L, Tsou C-J, Wu W-B: Vascular endothelial growth factor induces cxcl1 chemokine release via jnk and pi-3k-dependent pathways in human lung carcinoma epithelial cells. International J Mol Sci 2013;14:10090-10106.

20 Shieh J-M, Huang T-F, Hung C-F, Chou K-H, Tsai Y-J, Wu W-B: Activation of c-jun n-terminal kinase is essential for mitochondrial membrane potential change and apoptosis induced by doxycycline in melanoma cells. Br J Pharmacol 2010;160:1171-1184.

21 Green MR, Sambrook J: Molecular cloning: A laboratory mannul, ed 4. Cold Spring Habor Laboratory Press, 2012.

22 Chen C-P, Hung C-F, Lee S-C, Lo H-M, Wu P-H, Wu W-B: Lycopene binding compromised pdgf-aa/-ab signaling and migration in smooth muscle cells and fibroblasts: Prediction of the possible lycopene binding site within pdgf. Naunyn-Schmiedeberg's Arch Pharmacol 2010;381:401-414.

23 Kumar S, Jiang MS, Adams JL, Lee JC: Pyridinylimidazole compound sb 203580 inhibits the activity but not the activation of p38 mitogen-activated protein kinase. Biochem Biophys Res Comm 1999;263:825-831.

-24 Lo H-m, Lai T-h, Li C-h, Wu W-b: Tnf-[alpha] induces cxcl1 chemokine expression and release in human vascular endothelial cells in vitro via two distinct signaling pathways. Acta Pharmacol Sin 2014;35:339-350.

-25 Issa R, Xie S, Khorasani N, Sukkar M, Adcock IM, Lee K-Y, Chung KF: Corticosteroid inhibition of growth-related oncogene protein- $\alpha$ via mitogen-activated kinase phosphatase-1 in airway smooth muscle cells. J Immunol 2007;178:7366-7375.

26 Blobe GC, Schiemann WP, Lodish HF: Role of transforming growth factor $\beta$ in human disease. New Engl J Med 2000;342:1350-1358.

27 de Caestecker MP, Piek E, Roberts AB: Role of transforming growth factor- $\beta$ signaling in cancer. J Nat Cancer Instit 2000;92:1388-1402.

28 Jeon H-S, Jen J: Tgf-[beta] signaling and the role of inhibitory smads in non-small cell lung cancer. J Thorac Oncol 2010;5:417-419.

-29 Moustakas A, Heldin C-H: The regulation of tgf $\beta$ signal transduction. Development 2009;136:3699-3714.

-30 Babbar N, Hacker A, Huang Y, Casero RA Jr: Tumor necrosis factor alpha induces spermidine/spermine n1-acetyltransferase through nuclear factor kappab in non-small cell lung cancer cells. J Biol Chem 2006;281:2418224192.

-31 Berkova N, Lair-Fulleringer S, Femenia F, Huet D, Wagner MC, Gorna K, Tournier F, Ibrahim-Granet O, Guillot J, Chermette R, Boireau P, Latge JP: Aspergillus fumigatus conidia inhibit tumour necrosis factor- or staurosporine-induced apoptosis in epithelial cells. Int Immunol 2006;18:139-150.

-32 Anisowicz A, Messineo M, Lee SW, Sager R: An nf-kappa b-like transcription factor mediates il-1/tnf-alpha induction of gro in human fibroblasts. J Immunol 1991;147:520-527.

-33 Hao Q Wang L, Tang H: Vascular endothelial growth factor induces protein kinase d-dependent production of proinflammatory cytokines in endothelial cells. Am J Physiol - Cell Physiol 2009;296:C821-C827.

-34 Murakami K, Ueno A, Yamanouchi K, Kondo T: Thrombin induces groomgsa production in human umbilical vein endothelial cells. Thrombosis Res 1995;79:387-394. 